\title{
Kolkhoung (Pistacia khinjuk) Hull Oil and Kernel Oil as Antioxidative Vegetable Oils with High Oxidative Stability and Nutritional Value
}

\author{
Maryam Asnaashari ${ }^{1}$, Seyed Mohammad Bagher Hashemi ${ }^{2 *}$, Hamed Mahdavian Mehr ${ }^{3}$ \\ and Seyed Hossein Asadi Yousefabad ${ }^{4}$ \\ ${ }^{1}$ Department of Food Science and Technology, Sari Agricultural Sciences and \\ Natural Resources University (SANRU), Sari, Iran \\ ${ }^{2}$ Department of Food Science and Technology, College of Agriculture, Fasa University, Fasa, Iran \\ ${ }^{3}$ Ferdowsi University of Mashhad, Faculty of Agriculture, Department of Food Science and Technology, \\ Mashhad, Iran \\ ${ }^{4}$ Department of Food Science and Technology, College of Agriculture, Shiraz University, Shiraz, Iran
}

Received: May 8, 2014 Accepted: January 8, 2015

\begin{abstract}
Summary
In this study, in order to introduce natural antioxidative vegetable oil in food industry, the kolkhoung hull oil and kernel oil were extracted. To evaluate their antioxidant efficiency, gas chromatography analysis of the composition of kolkhoung hull and kernel oil fatty acids and high-performance liquid chromatography analysis of tocopherols were done. Also, the oxidative stability of the oil was considered based on the peroxide value and anisidine value during heating at 100,110 and $120^{\circ} \mathrm{C}$. Gas chromatography analysis showed that oleic acid was the major fatty acid of both types of oil (hull and kernel) and based on a low content of saturated fatty acids, high content of monounsaturated fatty acids, and the ratio of $\omega-6$ and $\omega-3$ polyunsaturated fatty acids, they were nutritionally well-balanced. Moreover, both hull and kernel oil showed high oxidative stability during heating, which can be attributed to high content of tocotrienols. Based on the results, kolkhoung hull oil acted slightly better than its kernel oil. However, both of them can be added to oxidation-sensitive oils to improve their shelf life.
\end{abstract}

Key words: chemical composition, hull oil, kernel oil, kolkhoung (Pistacia khinjuk), oxidative stability

\section{Introduction}

Oxidation rancidity is one of the most critical factors affecting the shelf life of processed foods. Polyunsaturated fatty acids are attacked by oxygen to form hydroperoxides, which then decompose further to cause off-flavour and produce many secondary products such as epoxy hydroperoxides, ketohydroperoxides, dihydroperoxides, cyclic peroxides and bicyclic endoperoxides, which in turn break up to form volatile compounds. The off-fla- vour compounds make oil less acceptable, or even unacceptable, to consumers as a food ingredient (1). Oxidation of oil also destroys essential fatty acids and produces toxic compounds and oxidized polymers (2). Indeed, oxidative stability of oil is the resistance to oxidation during processing and storage. Resistance to oxidation as an important indicator to determine oil shelf life and its quality can be expressed as the period of time necessary to reach the critical point of oxidation, whether it is a sensorial change or a sudden acceleration of the oxidative process. 
Therefore, oxidation of edible oil is very important in terms of palatability, nutritional quality and safety (3). Antioxidants are of interest to the food industry because of their organoleptic preservation properties and inhibition of rancidity. In a conventional way, some synthetic antioxidants such as butylated hydroxyanisole (BHA), butylated hydroxytoluene (BHT) and tert-butylhydroquinone (TBHQ) are used to prevent oxidative rancidity of oils and fats. However, several papers reported the adverse effects of these synthetic antioxidants such as liver damage and carnicogenesis. As a consequence, natural antioxidants in fruits and vegetables have become interesting among consumers and the scientific community, who are trying to identify safe sources of dietary antioxidants $(4,5)$.

The genus Pistacia belongs to the Anacardiaceae, a cosmopolitan family which comprises about 70 genera and over 600 species. Three Pistacia species which naturally grow in Iran are $P$. vera L., $P$. khinjuk Stocks and $P$. atlantica Desf. The species Pistacia atlantica and P. khinjuk are called bene and kolkhoung, respectively, in Persian language (6). Different parts of P. khinjuk have been investigated for various pharmacological activities such as antidiabetic, antitumour and anticholinesterase activities and beneficial effects on liver and lowering HDL and LDL levels (7). In traditional Iranian medicine, P. khinjuk is used as helpful remedy for different disorders including stomach discomfort, vomiting, nausea and motion sickness (8). Moreover, different studies assert the antimicrobial and antifungal activities of $P$. khinjuk due to some active constituents of essential oil including $\alpha$-pinene, $\beta$-pinene, myrcene, $\alpha$-terpineol, $\beta$-caryophyllene, masticadienonic acid, masticadienolic acid, morolic acid, germacrene B, and spathulenol (9). Since synthetic antioxidants may have adverse effects on human health, while P. khinjuk oil has shown some medicinal properties, the purpose of this study is to introduce the P. khinjuk oil (hull and kernel) and compare their chemical composition, natural antioxidant content and oxidation stability during heating at 100,110 and $120^{\circ} \mathrm{C}$. Peroxide value was used to determine the concentration of hydroperoxides formed in the initial stage of lipid oxidation, and anisidine value to determine the secondary oxidation products.

\section{Materials and Methods}

\section{Materials}

Kolkhoung (Pistacia khinjuk) fruit samples were gathered from the forest areas of Meimand and Marvdasht, Iran, and stored at $-18{ }^{\circ} \mathrm{C}$ until the beginning of experiments. All chemicals and solvents used in this study were of analytical reagent grade and purchased from Merck (Darmstadt, Germany) and Sigma-Aldrich (St. Louis, MO, USA) chemical companies.

\section{Oil extraction}

After drying at $40{ }^{\circ} \mathrm{C}$ in the shade, the hull and the kernel of the P. khinjuk were separated from each other. The hulls and kernels were ground to powder in a grinder. The powders were extracted with $n$-hexane (1:4 mass per volume) by agitation in a dark place at ambient tem- perature for $48 \mathrm{~h}$. The solvent was evaporated to dryness in vacuum at $40^{\circ} \mathrm{C}(10)$.

\section{Chemical composition}

Fatty acid composition of the P. khinjuk hull oil and kernel oil was determined by gas-liquid chromatography and was reported as relative area percentages. Fatty acid compositions of the hull oil and kernel oil were transesterified into their corresponding fatty acid methyl esters (FAME) by vigorous shaking of a solution of oil in $n$-hexane $(0.3 \mathrm{~g}$ in $7 \mathrm{~mL})$ with $2 \mathrm{~mL}$ of $7 \mathrm{M}$ methanolic potassium hydroxide at $50-55{ }^{\circ} \mathrm{C}$ for $10 \mathrm{~min}$. After shaking, the solution was allowed to settle for $5 \mathrm{~min}$. The upper layer was collected for gas chromatography (GC) analysis after mixing with anhydrous natrium sulphate and filtering. The FAME were identified using an HP-5890 chromatograph (Hewlett-Packard, Ramsey, MN, USA) equipped with a CP-SIL 88 (Supelco, Bellefonte, PA, USA) capillary column of fused silica, $60 \mathrm{~m} \times 0.32 \mathrm{~mm}$ i.d., $0.2 \mathrm{~mm}$ film thickness, and a flame ionization detector (FID). Helium was used as carrier gas with a flow rate of $1 \mathrm{~mL} / \mathrm{min}$. The oven temperature was maintained at $198{ }^{\circ} \mathrm{C}$, and that of the injector and the detector at $250{ }^{\circ} \mathrm{C}(11)$. The calculated oxidizability (Cox) value of P. khinjuk hull oil and kernel oil was calculated by the percentage of unsaturated C18 fatty acids, applying the formula proposed by Fatemi and Hammond (12):

$$
\operatorname{Cox}=[1(18: 1 \%)+10.3(18: 2 \%)+21.6(18: 3 \%)] / 100
$$

\section{HPLC analysis of tocopherols}

The content of tocopherols in the hull oil and kernel oil from P. khinjuk was determined using a high-performance liquid chromatograph (Waters, Alliance system, Milford, CT, USA) with a Spherisorb column $(25 \mathrm{~cm} \times 4$ $\mathrm{mm}$ i.d., Waters) packed with silica ( $5 \mu \mathrm{m}$ particle size) and a fluorescence detector operating at an excitation wavelength of $290 \mathrm{~nm}$ and an emission wavelength of 330 $\mathrm{nm}$ (13). The mobile phase was hexane/isopropanol, in the ratio of $98.5: 0.5$, by volume, at a flow rate of $1 \mathrm{~mL} / \mathrm{min}$. The tocopherols in the test samples were verified by comparison of their retention times with those of reference standards (ISO9936) (13).

\section{Oil oxidation}

Hull oil and kernel oil from P. khinjuk (5 g) were stored separately in a 1-mm layer in a Petri dish with a diameter of $9 \mathrm{~cm}$ at 100, 110 and $120^{\circ} \mathrm{C}$. Progress of oxidation was monitored by the determination of peroxide value and anisidine value during 36 days.

\section{Peroxide value}

The peroxide value (PV) of hull oil and kernel oil from $P$. khinjuk was measured spectrophotometrically at $500 \mathrm{~nm}$ by UV-VIS spectrophotometer (model 160A, Shimadzu, Tokyo, Japan). The oil samples were mixed with $9.8 \mathrm{~mL}$ of chloroform/methanol (7:3 by volume) on a vortex mixer for 2-4 s. Ammonium thiocyanate solution (50 $\mathrm{mL}, 30 \%$ mass per volume) and $50 \mathrm{~mL}$ of iron(II) chloride solution [ $(0.4 \mathrm{~g}$ of barium chloride dihydrate dissolved in $50 \mathrm{~mL}$ of $\left.\mathrm{H}_{2} \mathrm{O}\right)+\left(0.5 \mathrm{~g} \mathrm{FeSO}_{4} \cdot 7 \mathrm{H}_{2} \mathrm{O}\right.$ dissolved in $50 \mathrm{~mL}$ of $\left.\mathrm{H}_{2} \mathrm{O}\right)+2 \mathrm{~mL}$ of $10 \mathrm{M} \mathrm{HCl}$, with the precipitate, barium sul- 
phate, filtered off to produce a clear solution] were added, respectively, and after adding each of them, the sample was mixed on a vortex mixer for 2-4 s. Then, the absorbance of the sample was read after 5 min of incubation at room temperature. Results were expressed in milliequivalents of oxygen (meq $\mathrm{O}_{2}$ ) per kilogram of oil (14).

\section{Anisidine value}

The anisidine value (AV) was determined by reading the absorbance (at $350 \mathrm{~nm}$ ) of a solution resulting from reaction of 0.500 to $(4 \pm 0.001) \mathrm{g}$ of hull or kernel oil from $P$. khinjuk in $25 \mathrm{~mL}$ of isooctane and treated with $1 \mathrm{~mL}$ of $p$ -anisidine reagent (15).

\section{Statistical analysis}

All determinations were carried out in triplicate, and data were subjected to analysis of variance (ANOVA). ANOVA analyses were performed using SAS software University Edition (SAS Institute Inc., Cary, NC, USA). Significant differences between mean values were determined by Duncan's multiple range tests; p-values less than 0.05 were considered statistically significant.

\section{Results and Discussion}

\section{Chemical characteristics of kolkhoung hull oil and kernel oil}

Chemical characteristics of the hull oil and kernel oil from kolkhoung used in this study are shown in Table 1. The fatty acid composition of the oil is an important determination of its oxidation stability and nutritive value.

Table 1. Chemical characteristics of kolkhoung hull oil and kernel oil

\begin{tabular}{lcc}
\hline \multirow{2}{*}{ Fatty acid } & \multicolumn{2}{c}{$w / \%$} \\
\cline { 2 - 3 } & Hull oil & Kernel oil \\
\hline C12:0 & - & 0.22 \\
C14:0 & 0.65 & 0.20 \\
C16:0 & 19.44 & 16.11 \\
C18:0 & 0.42 & - \\
C18:1 & 63.55 & 61.11 \\
C18:2 & 13.57 & 20.09 \\
C18:3 & 1.50 & 1.14 \\
C20:0 & - & 0.18 \\
C22:0 & 0.87 & 0.94 \\
Others & 0.00 & 0.00 \\
SFA & 21.38 & 17.66 \\
MUFA & 63.55 & 61.11 \\
PUFA & 15.07 & 21.23 \\
PUFA/SFA & 0.70 & 1.20 \\
MUFA/PUFA & 4.22 & 2.88 \\
USFA/SFA & 3.68 & 4.66 \\
C18:2/C18:3 & 9.06 & 17.67 \\
Cox value & 2.36 & 2.93 \\
\hline & & \\
\hline
\end{tabular}

Also, the analysis of the oil composition helps to assess its purity. The hull oil mainly contained oleic, palmitic, linoleic, linolenic, behenic, myristic and stearic acids. Among its fatty acids, the highest percentage of the saturated, monounsaturated and polyunsaturated fatty acids (SFA, MUFA and PUFA) was of palmitic acid (19.44\%), oleic acid $(63.55 \%)$ and linoleic acid (13.57 \%), respectively. The kolkhoung kernel oil mostly included oleic $(61.11 \%)$, linoleic $(20.09 \%)$, palmitic $(16.11 \%)$, linolenic $(1.14 \%)$, behenic $(0.94 \%)$, lauric $(0.22 \%)$, myristic $(0.20 \%)$ and arachidic $(0.18 \%)$ acids. The highest percentage of SFA, MUFA and PUFA in kernel oil was of palmitic, oleic and linoleic acids (Table 1). Indeed, oleic acid was the dominant fatty acid in both kolkhoung hull oil and kernel oil. The fatty acid composition of the hull oil and kernel oil from P. khinjuk determined in this study was in accordance with the data reported in the literature (16). The PUFA/SFA ratio of kernel oil (1.20) was higher than of hull oil (0.70), which shows higher nutritive value of $P$. khinjuk kernel oil in comparison with hull oil. On the other hand, the MUFA/PUFA ratio of kernel oil (2.88) was lower than of hull oil (4.22). This ratio is a measure of oil tendency to oxidation. Higher ratio of the acids shows better oxidative stability of oil, especially during frying. So, the kolkhoung hull oil performs better than its kernel oil during frying. Moreover, P. khinjuk oils are edible vegetable oil types that are nutritionally well-balanced, based on a low content of SFA, a high content of MUFA, and a ratio of $\omega-6$ and $\omega-3$ PUFA. High amounts of unsaturated fatty acids, especially oleic and linoleic acids, make P. khinjuk oil (hull and kernel) important functional food. Also, Cox value of hull oil and kernel oil is 2.3 and 2.9, respectively, which indicates greater tendency of kernel oil towards autoxidation in comparison with hull oil. Tavakoli and Haddad Khodaparast (16) also evaluated the fatty acid composition of three Pistacia species growing in Iran including Pistacia vera, Pistacia atlantica and Pistacia khin$j u k$. The results show that the major fatty acid components characterized in the these oil types were oleic (52.03$52.12 \%)$, palmitic $(22.55-23.40 \%)$, palmitoleic (7.74-14.05 $\%)$, linoleic (5.35-12.02\%), stearic (2.39-3.00\%) and linolenic (1.16-1.50\%) acids, but negligible amounts of margaric $(0.05-0.40 \%)$, margaroleic $(0.20-0.24 \%)$ and gadoleic $(0.25-0.76 \%)$ acids.

\section{Composition of tocols in kolkhoung hull and kernel oil}

Tocols (tocopherol and tocotrienol) constitute a series of related benzopyranols that occur in plant tissues and vegetable oil and are powerful lipid-soluble antioxidants that act as vitamins and antioxidant agents. These compounds are only synthesized by plants and other oxygenic photosynthetic organisms, but they are essential components of the diet of animals. Tocopherols are present in all photosynthetic organisms, but tocotrienols are found only in certain plant families. Total tocol content of kolkhoung hull oil $(2159.1 \mathrm{mg} / \mathrm{kg}$ ) was slightly higher than of its kernel oil (2036.6 mg/kg) (Table 2). Kolkhoung is considered a valuable source of tocols because their content reported in this oil is much higher than that of common oil such as sunflower, cottonseed, soybean, canola and palm oil. There was also a significant difference in the kolkhoung tocol composition in comparison with other vegetable oils. Kolkhoung hull oil and kernel oil contain a high level of tocotrienols, which are structural analogues 
Table 2. Tocopherol composition of kolkhoung hull oil and seed oil

\begin{tabular}{lrc}
\hline \multirow{2}{*}{ Compound } & \multicolumn{2}{c}{$w /(\mathrm{mg} / \mathrm{kg})$} \\
\cline { 2 - 3 }$\alpha$-Tocopherol & Hull oil & Kernel oil \\
$\beta$-Tocopherol & 41.0 & 36.2 \\
$\gamma$-Tocopherol & 60.8 & 58.3 \\
$\delta$-Tocopherol & 4.4 & 3.1 \\
$\alpha$-Tocotrienol & 58.9 & 53.4 \\
$\beta$-Tocotrienol & 1112.6 & 1088.8 \\
Total & 881.4 & 796.8 \\
\hline
\end{tabular}

of tocopherols and are present in greater amounts in kolkhoung hull (1112.6 and $881.4 \mathrm{mg} / \mathrm{kg}$ of $\alpha$-tocotrienol and $\beta$-tocotrienol, respectively) and kernel oil ( $\alpha$-tocotrienol $1088.8 \mathrm{mg} / \mathrm{kg}$ and $\beta$-tocotrienol $881.4 \mathrm{mg} / \mathrm{kg}$ ) than other vegetable oils including palm, soya bean, corn, sunflower and rapeseed oil. Tocotrienols are known to possess a higher antioxidant activity than tocopherols and they may have benefits in protecting the skin against free radical peroxidation as well as cardioprotective, neuroprotective and anticancer properties. The tocol composition of $P$. khinjuk hull oil, which contains $\alpha$-tocopherol $(41 \mathrm{mg} / \mathrm{kg}$ ), $\beta$-tocopherol $(60.84 \mathrm{mg} / \mathrm{kg}), \gamma$-tocopherol $(4.4 \mathrm{mg} / \mathrm{kg}), \delta$ tocopherol $(58.91 \mathrm{mg} / \mathrm{kg}), \alpha$-tocotrienol $(1112.6 \mathrm{mg} / \mathrm{kg}$ ) and $\beta$-tocotrienol $(881.4 \mathrm{mg} / \mathrm{kg})$, is slightly higher than of kernel oil. However, both kolkhoung oil types are completely unique among common edible oils. In fact, the presence of tocols (tocopherol and tocotrienol) in kolkhoung oil suggests that there are potential benefits in using this oil in pharmaceutical industry.

\section{Oxidative stability of kolkhoung hull and kernel oil}

Table 3 shows the PV and AV of the kolkhoung hull oil samples during storage at different temperatures (100, 110 and $120^{\circ} \mathrm{C}$ ). Hydroperoxides are the primary products of lipid peroxidation. It is well known that hydroper- oxides have no undesirable flavour, whereas their decomposed products are mostly responsible for rancid off-flavour. As seen in Table 3, PV of kolkhoung hull oil samples increased from the beginning of the storage period to the last day, showing the progression of oxidation with the increase of temperature. The PV of kolkhoung hull oil samples stored at $100{ }^{\circ} \mathrm{C}$ after 16 days reached $12.02 \mathrm{meq}$ $\mathrm{O}_{2}$ per $\mathrm{kg}$ of oil and the difference between the PVs of the samples at all time intervals was significant. However, at $110{ }^{\circ} \mathrm{C}$ the PV of the samples increased slowly (2.79 to 19.07 meq $\mathrm{O}_{2}$ per $\mathrm{kg}$ of oil) in the first 16 days, but after 36 days it reached 41.1 meq $\mathrm{O}_{2}$ per $\mathrm{kg}$ of oil. The rate of hydroperoxide formation at $120{ }^{\circ} \mathrm{C}$ was faster than at the other two temperatures $\left(100\right.$ and $\left.110^{\circ} \mathrm{C}\right)$. In fact, temperature is the main factor of the oil oxidation rate, since oxidation, which starts with the abstraction of hydrogen adjacent to a double bond in a fatty acid, is catalyzed by light and heat to form a free radical. Hydroperoxides are more stable than radical species, leading to secondary oxidation products including aldehydes, ketones, acids, alcohols and lactones. Secondary products are responsible for impaired taste and flavour of oil. Indeed, when hydroperoxides break down, they produce volatile aldehydes like hexanal, leaving behind a nonvolatile portion of the fatty acid that remains part of the lipid molecules. These nonvolatile reaction products can be measured by the reaction with anisidine. The changes of AV of kolkhoung hull oil at the three temperatures are shown in Table 3. As we expected, the formation of volatile aldehydes at higher temperature $\left(120^{\circ} \mathrm{C}\right)$ was greater compared to lower temperature $\left(100\right.$ and $\left.110^{\circ} \mathrm{C}\right)$. Therefore, the AV of kolkhoung hull oil at $120{ }^{\circ} \mathrm{C}$ increased for $672 \%$, while at 110 and $100{ }^{\circ} \mathrm{C}$ it increased for 575 and $440 \%$, respectively. The changes of PV and AV of kolkhoung kernel oil samples at 100,110 and $120{ }^{\circ} \mathrm{C}$ are shown in Table 4 . The kolkhoung kernel oil samples showed a similar trend of changes in the PV and AV with heating time compared to hull oil. The increase of kolkhoung kernel oil PV was 1064,116 and $1358 \%$ at 100,110 and $120{ }^{\circ} \mathrm{C}$, respectively. As a consequence, as storage temperature increased, the

Table 3. The peroxide value (PV) and anisidine value (AV) of kolkhoung hull oil during heating at 100,110 and $120^{\circ} \mathrm{C}$

\begin{tabular}{|c|c|c|c|c|c|c|}
\hline \multirow{3}{*}{ Time/h } & \multicolumn{6}{|c|}{ Temperature $/{ }^{\circ} \mathrm{C}$} \\
\hline & \multicolumn{2}{|c|}{100} & \multicolumn{2}{|c|}{110} & \multicolumn{2}{|c|}{120} \\
\hline & $\begin{array}{l}\mathrm{PV} /\left(\mathrm{meq} \mathrm{O}_{2}\right. \\
\text { per kg of oil) }\end{array}$ & $\mathrm{AV}$ & $\begin{array}{l}\mathrm{PV} /\left(\text { meq } \mathrm{O}_{2}\right. \\
\text { per kg of oil) }\end{array}$ & $\mathrm{AV}$ & $\begin{array}{l}\mathrm{PV} /\left(\text { meq } \mathrm{O}_{2}\right. \\
\text { per kg of oil) }\end{array}$ & $\mathrm{AV}$ \\
\hline 0 & $(2.79 \pm 0.06)^{\mathrm{iB}}$ & $(3.80 \pm 0.07)^{\mathrm{jA}}$ & $(2.79 \pm 0.06)^{\mathrm{iB}}$ & $(3.86 \pm 0.07)^{\mathrm{jA}}$ & $(2.79 \pm 0.06)^{\mathrm{B}}$ & $(3.86 \pm 0.07)^{\mathrm{iA}}$ \\
\hline 4 & $(5.10 \pm 0.05)^{\mathrm{iE}}$ & $(4.92 \pm 0.07)^{\mathrm{iF}}$ & $(5.96 \pm 0.07)^{\mathrm{iB}}$ & $(5.28 \pm 0.05)^{\mathrm{iD}}$ & $(6.60 \pm 0.05)^{\mathrm{iA}}$ & $(5.81 \pm 0.05)^{\mathrm{iC}}$ \\
\hline 8 & $(7.60 \pm 0.07)^{\mathrm{hD}}$ & $(5.80 \pm 0.05)^{\mathrm{hF}}$ & $(8.87 \pm 0.06)^{\mathrm{Hb}}$ & $(6.35 \pm 0.06)^{\mathrm{hE}}$ & $(13.30 \pm 0.09)^{\mathrm{hA}}$ & $(9.30 \pm 0.04)^{\mathrm{hC}}$ \\
\hline 12 & $(10.11 \pm 0.05)^{\mathrm{gD}}$ & $(7.090 \pm 0.06)^{\mathrm{gF}}$ & $(15.04 \pm 0.09)^{\mathrm{gB}}$ & $(9.80 \pm 0.07)^{\mathrm{gE}}$ & $(17.90 \pm 0.07)^{\mathrm{gA}}$ & $(12.10 \pm 0.07)^{\mathrm{gC} C}$ \\
\hline 16 & $(12.02 \pm 0.08)^{\mathrm{fE}}$ & $(8.40 \pm 0.07)^{\mathrm{fF}}$ & $(19.07 \pm 0.06)^{\mathrm{fB}}$ & $(12.80 \pm 0.04)^{\mathrm{fD}}$ & $(22.40 \pm 0.07)^{\mathrm{fA}}$ & $(15.05 \pm 0.05)^{\mathrm{fC}}$ \\
\hline 20 & $(18.60 \pm 0.07)^{\mathrm{eC}}$ & $(11.70 \pm 0.07)^{\mathrm{eF}}$ & $(23.80 \pm 0.08)^{\mathrm{Eb}}$ & $(15.60 \pm 0.02)^{\mathrm{eE}}$ & $(27.02 \pm 0.06)^{\mathrm{eA}}$ & $(17.92 \pm 0.07)^{\mathrm{eD}}$ \\
\hline 24 & $(23.00 \pm 0.05)^{\mathrm{dC}}$ & $(13.90 \pm 0.04)^{\mathrm{dF}}$ & $(28.20 \pm 0.09)^{\mathrm{Db}}$ & $(18.40 \pm 0.07)^{\mathrm{dE}}$ & $(31.60 \pm 0.07)^{\mathrm{dA}}$ & $(21.05 \pm 0.07)^{\mathrm{dD}}$ \\
\hline 28 & $(27.60 \pm 0.12)^{\mathrm{cC}}$ & $(15.90 \pm 0.06)^{\mathrm{cF}}$ & $(32.70 \pm 0.09)^{\mathrm{CB}}$ & $(21.4 \pm 0.09)^{\mathrm{cE}}$ & $(36.20 \pm 0.07)^{\mathrm{cA}}$ & $(24.06 \pm 0.06)^{\mathrm{cD}}$ \\
\hline 32 & $(32.80 \pm 0.10)^{\mathrm{bC}}$ & $(18.10 \pm 0.16)^{\mathrm{bF}}$ & $(37.50 \pm 0.13)^{\mathrm{Bb}}$ & $(22.9 \pm 0.09)^{\mathrm{bE}}$ & $(40.77 \pm 0.07)^{\mathrm{bA}}$ & $(27.12 \pm 0.10)^{\mathrm{bD}}$ \\
\hline 36 & $(39.03 \pm 0.12)^{\mathrm{aC}}$ & $(20.50 \pm 0.07)^{\mathrm{aF}}$ & $(41.10 \pm 0.13)^{\mathrm{Ab}}$ & $(26.05 \pm 0.11)^{\mathrm{aE}}$ & $(44.8 \pm 0.08)^{\mathrm{aA}}$ & $(29.80 \pm 0.06)^{\mathrm{aD}}$ \\
\hline
\end{tabular}

Mean values \pm S.D. (standard deviation) within a column with the same lowercase letters are not significant at $p<0.05$

Mean values \pm S.D. (standard deviation) within a row with the same uppercase letters are not significant at $\mathrm{p}<0.05$ 
Table 4. The peroxide value (PV) and anisidine value (AV) of the kolkhoung kernel oil during at heating process 100,110 and $120{ }^{\circ} \mathrm{C}$

\begin{tabular}{|c|c|c|c|c|c|c|}
\hline \multirow{3}{*}{ Time/h } & \multicolumn{6}{|c|}{ Temperature $/{ }^{\circ} \mathrm{C}$} \\
\hline & \multicolumn{2}{|c|}{100} & \multicolumn{2}{|c|}{110} & \multicolumn{2}{|c|}{120} \\
\hline & $\begin{array}{l}\mathrm{PV} /\left(\mathrm{meq} \mathrm{O}_{2}\right. \\
\text { per kg of oil) }\end{array}$ & AV & $\begin{array}{l}\mathrm{PV} /\left(\mathrm{meq} \mathrm{O}_{2}\right. \\
\text { per kg of oil) }\end{array}$ & AV & $\begin{array}{l}\mathrm{PV} /\left(\mathrm{meq} \mathrm{O}_{2}\right. \\
\text { per kg of oil) }\end{array}$ & AV \\
\hline 0 & $(3.44 \pm 0.08)^{\mathrm{i}}$ & $(4.20 \pm 0.06)^{\mathrm{jA}}$ & $(3.44 \pm 0.08)^{\mathrm{iB}}$ & $(4.20 \pm 0.06)^{\mathrm{iA}}$ & $(3.44 \pm 0.08)^{\mathrm{iB}}$ & $(4.20 \pm 0.06)^{\mathrm{iA}}$ \\
\hline 4 & $(5.56 \pm 0.09)^{\mathrm{iC}}$ & $(5.08 \pm 0.08)^{\mathrm{iD}}$ & $(6.14 \pm 0.03)^{\mathrm{iB}}$ & $(5.66 \pm 0.07)^{\mathrm{iC}}$ & $(7.01 \pm 0.04)^{\mathrm{iA}}$ & $(6.17 \pm 0.05)^{\mathrm{iB}}$ \\
\hline 8 & $(7.85 \pm 0.03)^{\mathrm{hD}}$ & $(6.35 \pm 0.05)^{\mathrm{hF}}$ & $(9.12 \pm 0.04)^{\mathrm{hC}}$ & $(7.02 \pm 0.07)^{\mathrm{hE}}$ & $(15.60 \pm 0.07)^{\mathrm{hA}}$ & $(10.10 \pm 0.04)^{\mathrm{hB}}$ \\
\hline 12 & $(10.40 \pm 0.07)^{\mathrm{gE}}$ & $(7.84 \pm 0.04)^{\mathrm{gF}}$ & $(16.48 \pm 0.06)^{\mathrm{gB}}$ & $(11.05 \pm 0.10)^{\mathrm{gD}}$ & $(20.11 \pm 0.05)^{\mathrm{gA}}$ & $(13.20 \pm 0.08)^{\mathrm{gC}}$ \\
\hline 16 & $(12.47 \pm 0.05)^{\mathrm{fE}}$ & $(8.91 \pm 0.08)^{\mathrm{fF}}$ & $(20.88 \pm 0.06)^{\mathrm{fB}}$ & $(13.80 \pm 0.05)^{\mathrm{fD}}$ & $(26.30 \pm 0.08)^{\mathrm{fA}}$ & $(16.38 \pm 0.07)^{\mathrm{fC}}$ \\
\hline 20 & $(19.08 \pm 0.09)^{\mathrm{eD}}$ & $(12.94 \pm 0.07)^{\mathrm{eF}}$ & $(25.50 \pm 0.07)^{\text {ев }}$ & $(17.01 \pm 0.09)^{\mathrm{eE}}$ & $(30.90 \pm 0.08)^{\mathrm{eA}}$ & $(19.60 \pm 0.06)^{\mathrm{eC}}$ \\
\hline 24 & $(23.60 \pm 0.05)^{\mathrm{dC}}$ & $(16.25 \pm 0.05)^{\mathrm{dF}}$ & $(30.14 \pm 0.07)^{\mathrm{dB}}$ & $(20.03 \pm 0.05)^{\mathrm{dE}}$ & $(35.40 \pm 0.05)^{\mathrm{dA}}$ & $(22.90 \pm 0.08)^{\mathrm{dD}}$ \\
\hline 28 & $(28.20 \pm 0.06)^{\mathrm{cC}}$ & $(18.80 \pm 0.09)^{\mathrm{cF}}$ & $(34.07 \pm 0.10)^{\mathrm{cB}}$ & $(22.59 \pm 0.08)^{\mathrm{cE}}$ & $(40.30 \pm 0.14)^{\mathrm{cA}}$ & $(26.30 \pm 0.06)^{\mathrm{cD}}$ \\
\hline 32 & $(33.40 \pm 0.04)^{\mathrm{bC}}$ & $(19.91 \pm 0.09)^{\mathrm{bF}}$ & $(38.70 \pm 0.10)^{\mathrm{bB}}$ & $(25.63 \pm 0.08)^{\mathrm{bE}}$ & $(45.12 \pm 0.10)^{\mathrm{bA}}$ & $(29.70 \pm 0.06)^{\mathrm{bD}}$ \\
\hline 36 & $(40.05 \pm 0.14)^{\mathrm{aC}}$ & $(23.13 \pm 0.08)^{\mathrm{aF}}$ & $(43.36 \pm 0.09)^{\mathrm{aB}}$ & $(28.50 \pm 0.07)^{\mathrm{aE}}$ & $(50.17 \pm 0.13)^{\mathrm{aA}}$ & $(33.11 \pm 0.06)^{\mathrm{aD}}$ \\
\hline
\end{tabular}

Mean values \pm S.D. (standard deviation) within a column with the same lowercase letters are not significant at $\mathrm{p}<0.05$ Mean values \pm S.D. (standard deviation) within a row with the same uppercase letters are not significant at $\mathrm{p}<0.05$

rate of oxidation increased. Moreover, the rate of $\mathrm{AV}$ at $100{ }^{\circ} \mathrm{C}$ gently increased in $36 \mathrm{~h}$, while at $120{ }^{\circ} \mathrm{C}$ after 8 days it increased rapidly, so that the $\mathrm{AV}$ of kolkhoung kernel oil samples reached values of 23.1, 28.5 and 33.11 at 100,110 and $120{ }^{\circ} \mathrm{C}$, respectively. According to the Arrhenius equation, as the temperature increased, the energy of activation decreased (17). As a consequence, the rate of lipid oxidation also increased.

The results calculated from the linear relationship between the PV and AV and heating time of kolkhoung hull oil and kernel oil are shown in Table 5. The slope of the linear equations (a value), which were considered to be a measure of $\mathrm{PV}$ and $\mathrm{AV}$ rate, increased as the temperature rose from 100 to $120^{\circ} \mathrm{C}$. Thus, the PV changed from 1.0 to 1.17 in the hull oil and the AV increased from 0.48 to 0.74 . Moreover, hull oil samples stored at $100{ }^{\circ} \mathrm{C}$ showed the lowest oxidation rate $(\mathrm{a}=1.0)$, whereas kernel oil stored at $120{ }^{\circ} \mathrm{C}$ showed the lowest heating stability $(\mathrm{a}=1.30)$ based on hydroperoxide formation. Also, the oxidation rate of hull oil samples at all temperatures was slightly lower than of kolkhoung kernel oil, based on the AV. There are significant differences between the value of AV curve at 100,110 and $120^{\circ} \mathrm{C}$, so that the value of hull oil based on the $\mathrm{AV}$ changed from 0.48 to 0.74 , while the $\mathrm{AV}$ of kernel oil increased from 0.55 to 0.82 . This indicates slightly higher antioxidant potential of kolkhoung hull oil even at high temperature. In general, based on the formation of primary and secondary lipid peroxidation products, the oxidative stability of kolkhoung hull oil is slightly higher than of kernel oil. Regarding the high oxidative stability of kolkhoung hull oil and its high tocopherol and tocotrienol contents, it was expected that the addition of this oil to other vegetable oils can improve their oxidative stability. Tavakoli et al. (6) also compared the chemical characteristics of P. khinjuk hull oil, P. atlantica hull oil and Sesamum indicum L. cv. Dezful seed oil. The results indicated that the oxidation stability of P. khinjuk hull oil was based on conjugated diene hydroperoxides and carbonyl value during heating treatment $(8 \mathrm{~h})$ at $170{ }^{\circ} \mathrm{C}$ due to high content of tocotrienols ( $92.6 \%$ of total tocol compounds). The AV measured during heating was plotted against the PV (Fig. 1). There was a linear relationship between the AV and PV with a high determination coefficient $\left(\mathrm{R}^{2}=0.997\right)$. Determination of $\mathrm{AV}$ is convenient when applied to edible oil and fats, especially to detect 2,4-dienals. Unlike hydroperoxides, aldehydes do not break up rapidly, thus allowing the history of an oil to be determined with the AV.

Table 5. The results calculated from the linear relationship of the peroxide value (PV) and anisidine value (AV) with the heating time of kolkhoung hull and kernel oil at 100,110 and $120^{\circ} \mathrm{C}$

\begin{tabular}{|c|c|c|c|c|c|c|c|}
\hline \multirow{2}{*}{ Oil } & \multirow{2}{*}{$t /{ }^{\circ} \mathrm{C}$} & \multicolumn{3}{|c|}{$\mathrm{PV}=\mathrm{a}($ time $)+\mathrm{b}$} & \multicolumn{3}{|c|}{$\mathrm{AV}=\mathrm{a}($ time $)+\mathrm{b}$} \\
\hline & & $\mathrm{a}$ & $\mathrm{b}$ & $\mathrm{R}^{2}$ & $\mathrm{a}$ & B & $\mathrm{R}^{2}$ \\
\hline \multirow{3}{*}{ Hull } & 100 & $(1.01 \pm 0.00)^{\mathrm{fv}}$ & $(-0.27 \pm 0.01)^{\mathrm{f}}$ & 0.970 & $(0.48 \pm 0.00)^{\mathrm{f}}$ & $(2.40 \pm 0.08)^{\mathrm{e}}$ & 0.975 \\
\hline & 110 & $(1.10 \pm 0.00)^{\mathrm{d}}$ & $(1.62 \pm 0.05)^{d}$ & 0.997 & $(0.65 \pm 0.01)^{\mathrm{d}}$ & $(2.61 \pm 0.05)^{\mathrm{d}}$ & 0.991 \\
\hline & 120 & $(1.17 \pm 0.00)^{\mathrm{b}}$ & $(3.15 \pm 0.06)^{b}$ & 0.998 & $(0.74 \pm 0.00)^{\mathrm{b}}$ & $(3.35 \pm 0.06)^{b}$ & 0.999 \\
\hline \multirow{3}{*}{ Kernel } & 100 & $(1.02 \pm 0.00)^{\mathrm{e}}$ & $(0.06 \pm 0.04)^{\mathrm{e}}$ & 0.967 & $(0.55 \pm 0.00)^{\mathrm{e}}$ & $(2.37 \pm 0.06)^{\mathrm{e}}$ & 0.969 \\
\hline & 110 & $(1.18 \pm 0.00)^{\mathrm{c}}$ & $(2.12 \pm 0.05)^{\mathrm{c}}$ & 0.995 & $(0.71 \pm 0.00)^{c}$ & $(2.83 \pm 0.09)^{\mathrm{c}}$ & 0.993 \\
\hline & 120 & $(1.30 \pm 0.00)^{\mathrm{a}}$ & $(3.96 \pm 0.04)^{\mathrm{a}}$ & 0.995 & $(0.82 \pm 0.00)^{\mathrm{a}}$ & $(3.50 \pm 0.04)^{\mathrm{a}}$ & 0.998 \\
\hline
\end{tabular}

Mean values \pm S.D. (standard deviation) within a column with the same letters are not significant at $\mathrm{p}<0.05$ 


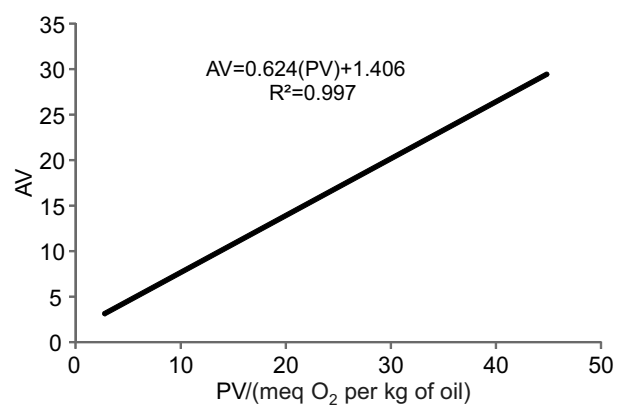

Fig 1. Correlation of the anisidine value (AV) with the peroxide value $(\mathrm{PV})$ in the kolkhoung hull oil at $120^{\circ} \mathrm{C}$ for $36 \mathrm{~h}$

\section{Conclusions}

Because of possible toxic and carcinogenic compounds of synthetic antioxidants like BHA, BHT and TBHQ, which are formed during their degradation, the application of the most widely used synthetic antioxidants has been questioned. The present study showed that the hull oil and kernel oil of kolkhoung, a species of pistachio growing wild in Iran, can be considered as a new source of safe and effective natural antioxidants and should be used in common oils to increase their shelf life. Our results also indicated that the kolkhoung hull oil was more resistant to lipid peroxidation than its kernel oil. This can be attributed to very high content of tocopherols and tocotrienols and very low amounts of USFA/SFA and Cox value compared to its kernel oil.

\section{References}

1. Sun $Y$, Wang W, Chen H, Li C. Autoxidation of unsaturated lipids in food emulsion. Food Sci Nutr. 2011;51:453-66. http://dx.doi.org/10.1080/10408391003672086

2. Fennema OR. Food chemistry. New York, NY, USA: Marcel Dekker, Inc.; 1996.

3. Shahidi F. Bailey's industrial oil and fat products. 6th edition. Hoboken, NJ, USA: Wiley Interscience Publication; 2005.

4. Suja KP, Abraham JT, Thamizh SN, Jayalekshmy A, Arumughan C. Antioxidant efficacy of sesame cake extract in vegetable oil protection. Food Chem. 2004;84:393-400. http://dx.doi.org/10.1016/S0308-8146(03)00248-6

5. Krings U, Saharty YSE, Zeany BAE, Pabel B, Berger RG. Antioxidant activity of extracts from roasted wheat germ.
Food Chem. 2000;71:91-5.

http://dx.doi.org/10.1016/S0308-8146(00)00148-5

6. Tavakoli J, Haddad Khodaparast MH, Aminlari M, Esmaeilzadeh Kenari R, Sharif A. Introducing Pistacia khinjuk (kolkhoung) fruit hull oil as a vegetable oil with special chemical composition and unique oxidative stability. Chem Nat Compd. 2013;49:803-10. http://dx.doi.org/10.1007/s10600-013-0752-4

7. Taran M, Sharifi M, Azizi E, Khanahmadi M. Antimicrobial activity of the leaves of Pistacia khinjuk. J Med Plants. 2010; 9:81-5.

8. Dob T, Dahmane D, Chelghoum C. Chemical composition of the essential oils of Pistacia lentiscus L. from Algeria. J Essent Oil Res. 2006; 18:335-8. http://dx.doi.org/10.1080/10412905.2006.9699105

9. Bahmani M, Eftekhari Z. An ethnoveterinary study of medicinal plants in treatment of diseases and syndromes of herd dog in southern regions of Ilam province, Iran. Com Clin Path. 2012;22:1-5.

http://dx.doi.org/10.1007/s00580-012-1423-8

10. Sharif A, Farhoosh R, Haddad Khodaparast MH, Tavassoli Kafrani MH. Antioxidant activity of bene oil compared with sesame and rice oils during the frying process of sunflower oil. J Food Lipids. 2009;16:394-406.

http://dx.doi.org/10.1111/j.1745-4522.2009.01154.x

11. Metcalf LC, Schmitz AF. Rapid preparation of methyl esters from lipid for chromatography analysis. Anal Chem. 1961; 33:363-4.

12. Fatemi SH, Hammond EG. Analysis of oleate, linoleate and linolenate hydroperoxides in oxidized ester mixtures. Lipids. 1980;15: 379-85. http://dx.doi.org/10.1007/BF02533555

13. ISO 9936:1997. Animal and vegetable fats and oils - Determination of tocopherols and tocotrienols contents - Method using high performance liquid chromatography. Geneva, Switzerland; 1997.

14. Shantha NC, Decker EA. Rapid, sensitive, iron-based spectrophotometric methods for determination of peroxide values of food lipids. J AOAC Int. 1994;77:421-4.

15. American Oil Chemist's Society. Official methods and recommended practices of the American Oil Chemists Society, 5th edition. Champaign, IL: AOCS Press; 1998.

16. Tavakoli J, Haddad Khodaparast MH. Chemical properties of the oil from Pistacia khinjuk fruits growing in Iran. Chem Nat Compd. 2013;49:546-50. http://dx.doi.org/10.1007/s10600-013-0667-0

17. Farhoosh R, Hoseini-Yazdi SZ. Shelf-life of olive oils using empirical models developed at low and high temperature. Food Chem. 2013;141:557-65. http://dx.doi.org/10.1016/j.foodchem.2013.03.024 